\title{
GeOPHYSICAL MEASUREMENTS AT SWEDISH AND Estonian LANDFILLS - CASE STUDIES FROM FOUR SITES
}

\author{
By J. Aaltonen and B. Olofsson \\ Div. of Land and Water Resources, Royal Institute of Technology, \\ S-100 44 Stockholm, Sweden.
}

\begin{abstract}
INTRODUCTION
Landfills have been, and are, the most used solution for waste disposal. There is, though, a growing concern about effects landfills have on the environment. A serious problem occurring is leakage, with its possibility to contaminate nearby aquifers. Monitoring the situation is mostly done by analyses of water samples. The control points are often located without sufficient hydrogeological knowledge, especially in geologically heterogeneous environments as in Sweden. To overcome this lack of information geophysics has been used as an areally covering method, to increase knowledge of hydrogeological systems and to detect and monitor leakage (Greenhouse \& Slaine, 1986; Nobes, 1996; Benson et. al., 1997 and others).
\end{abstract}

We will conclude experiences obtained at Swedish locations and one Estonian, where the geophysical data has improved the understanding of the hydrogeological system present. The main method has been direct current (DC) resistivity measurements, complemented with ground penetrating radar (GPR), very low frequency (VLF) and seismics. The landfills represent different geological surroundings, which all yield in different problems and results. The following case histories are from projects carried out during 1992-96. All investigations presented have used well-known geophysical knowledge and system configurations.

\section{Case I Tartu, Estonia}

A resistivity investigation was done at a landfill in Tartu in order to see if any low resistivity zones could be detected as an indication of possible leachate. The landfill lies in a polder area, with a dense network of ditches (Fig. 1). The geology comprehends sandstone, overlain by sandy loamy till, gravel and sand, with clay layers in the upper part. The overburden is covered by peat, 2 to $3 \mathrm{~m}$ thick. Groundwater levels (1.5 m below ground) slope from east to west, with a main flow from south-east to north-west. Chemical analyses have been done to a large extent, however, the samples are only surface water collected in ditches and do not show indications of leachate, due to conceivable dilution.

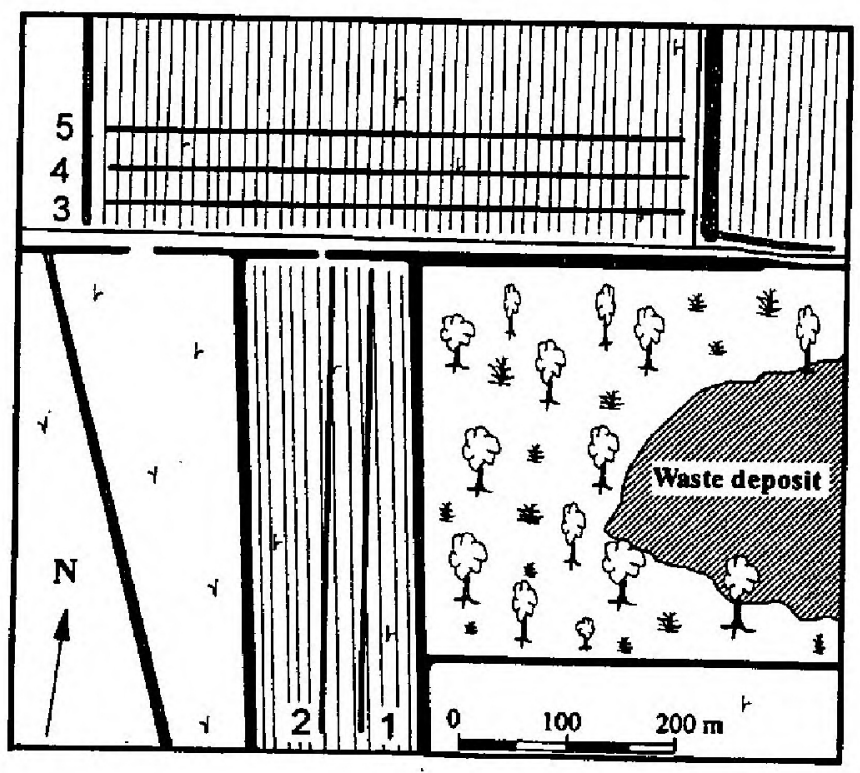

Figure 1. Map of the investigation site, Tartu, Estonia.
Geoelectrical profiling, completed with soundings, were only made in the hydrogeologically most interesting part at the north west corner (Fig. 1) because of a limited investigation time. Parallel profiles were made to confirm or reject a possible trend in the profiling. Profile 1 and 2 was made Iong, southwards, to ensure measurements in an unaffected environment.

The profiling was carried out using an electrode separation of $20 \mathrm{~m}$, which was considered suitable to reach and comprise the sand layers, underneath the peat, and the groundwater level.

Where the depth to the groundwater and the sand layer was known from the start, an estimation of the array length could be done without any preparatory VES. 